\title{
Saisonal und regional einkaufen
}

Es gibt viele Gründe saisonal und regional einzukaufen.

\section{Aber was heißt das denn genau: saisonal und regional?}

Regional kommt von Region.

Es bedeutet, dass man Obst und Gemüse vor allem aus der Region kaufen soll.

Saisonal kommt von Saison.

Das kennen viele vom Fuß•ball.

Saison ist beim Fuß•ball die Zeit, in der gespielt wird.

Wenn keine Saison ist, hat der Fuß•ball Pause. Im Winter ist es zu kalt, im Sommer zu heiß.

Ähnlich ist es auch mit Obst und Gemüse. Obst und Gemüse werden zu bestimmten Zeiten geerntet. Dann haben sie Saison. Manche Sorten können nach der Ernte im Lager aufbewahrt werden.

\section{Warum sollte man also saisonal} und regional kaufen?

\section{Es schmeckt besser.}

Das merkt man besonders gut zur Erd•beer-zeit. Vorher bekommt man schon Erd•beeren zu kaufen. Die kommen aus Ländern im Süden und mussten lange transportiert werden.

Die Erd•beeren schmecken nicht so gut, wie die Frischen, die ein paar Wochen später hier wachsen. Und wer schonmal Tief•kühl-erd•beeren probiert hat, weiß auch, dass die nicht so gut schmecken.

Weniger Transport bedeutet auch weniger Umweltoverschmutzung.

Außerdem hat so jede Jahreszeit auch ihren eigenen Geschmack. Erdbeeren im Frühling, Kürbis im Herbst, Äpfel und Nüsse im Winter. Das passt doch schon sehr gut zusammen, oder?

Mehr Infos haben auch die Verkäufer im Bio-Supermarkt.

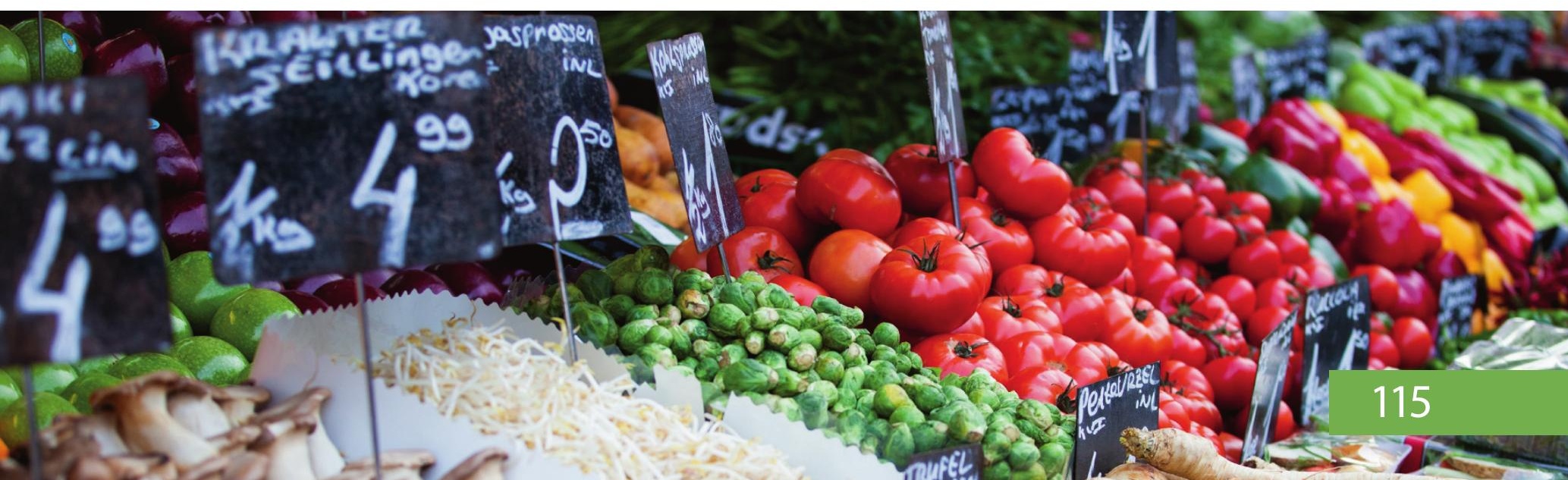

